\title{
Versatile Synthesis and Fluorescent Labeling of ZIF-90 Nanoparticles for Biomedical Applications
}

\author{
Christopher G. Jones, Vitalie Stavila, * Marissa A. Conroy, Patrick Feng, \\ Brandon V. Slaughter, Carlee E. Ashley, Mark D. Allendorf* \\ Sandia National Laboratories, Livermore, California, 94551 and Albuquerque, NM, 87123 \\ Corresponding Authors: \\ Vitalie Stavila, vnstavi@sandia.gov; Mark D. Allendorf, mdallen@sandia.gov.
}

\section{Table of Contents:}

Figure S1. Precipitate formed during standard room-temperature synthesis procedure............. S-2

Table S1. Reactions conditions for size ranges of ZIF-90 NPs and BET surface areas ........... S S-2

Table S2. Elemental analysis of ZIF-90 samples ......................................... S-2

Figure S2. SEM images of ZIF-90 particles syntehsized at room temperature ...................... S-3

Figure S3. PXRD patterns for ZIF-90 synthesized in the presence of various amines ............. S-3

Figure S4. SEM images of ZIF-90 particles synthesized with tributylamine . .................... S-4

Figure S5. SEM images of ZIF-90 particles synthesized with triethylamine . ..................... S-4

Figure S6. SEM images of ZIF-90 particles synthesized in trioctylamine at $150{ }^{\circ} \mathrm{C} \ldots \ldots \ldots \ldots . . . . .6-4$

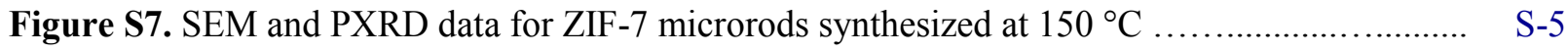

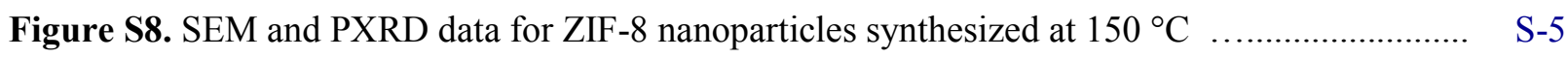

Figure S9. SEM and PXRD data for TIF-2 particles formed solvothermally at $150{ }^{\circ} \mathrm{C} \ldots \ldots \ldots \ldots . . \quad \mathrm{S}-6$

Figure S10. Photos of ZIF-90 particles labeled with Alexa Fluor ${ }^{\circledR}$ dyes ................................... S-6

Figure S11. PXRD patterns of ZIF-90 NPs before and after fluorescent labeling ....................... S-7

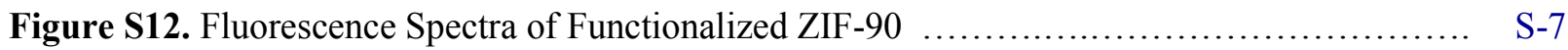

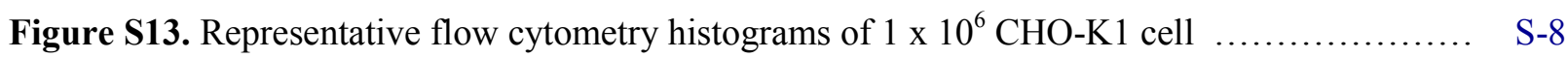



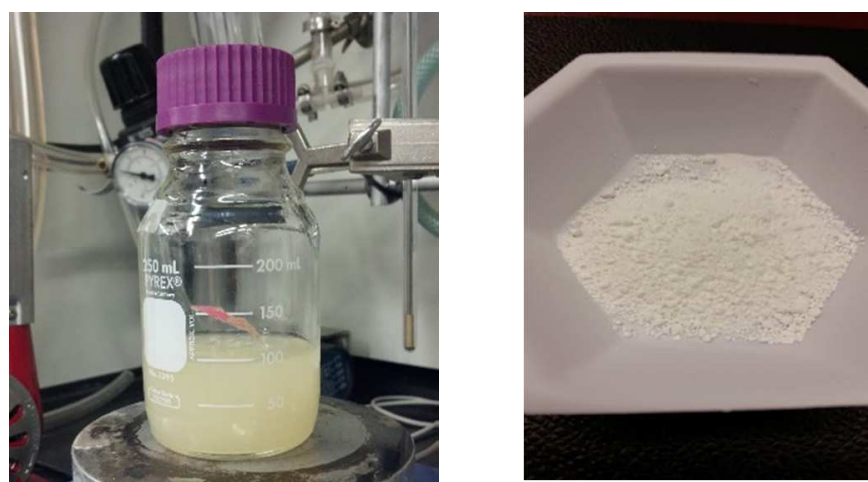

Figure S1. Precipitate formed during standard room-temperature synthesis procedure in DMF in the presence of TOA (left) and isolated dry ZIF-90 product (right).

Table S1. Reactions conditions for size ranges of ZIF-90 nanoparticles and BET surface areas.

\begin{tabular}{|l|c|c|c|c|}
\hline Size Range & BET, $\mathbf{~ m}^{2} / \mathbf{g}$ & Amine & Temperature & Reaction Time \\
\hline $30-50 \mathrm{~nm}$ & 1297 & Trioctylamine & $0{ }^{\circ} \mathrm{C}$ & 1 minute \\
\hline $60-90 \mathrm{~nm}$ & 1261 & Trioctylamine & $25^{\circ} \mathrm{C}$ & 1 minute \\
\hline $100-200 \mathrm{~nm}$ & 1180 & Tributylamine & $25^{\circ} \mathrm{C}$ & 1 minute \\
\hline $200-300 \mathrm{~nm}$ & 1145 & Triethylamine & $25^{\circ} \mathrm{C}$ & 1 minute \\
\hline $300-400 \mathrm{~nm}$ & 1164 & Trioctylamine & $100^{\circ} \mathrm{C}$ & 60 minutes \\
\hline $600-1000 \mathrm{~nm}$ & 1103 & Trioctylamine & $150^{\circ} \mathrm{C}$ & 60 minutes \\
\hline
\end{tabular}

Table S2. Elemental analysis of as-synthesized and surface-functionalized ZIF-90 samples.

\begin{tabular}{|l|c|c|c|}
\hline Sample & Carbon, wt $\%$ & Hydrogen, wt\% & Nitrogen, wt\% \\
\hline ZIF-90 (TOA) & 36.76 & 3.60 & 20.41 \\
\hline ZIF-90 + AF 633 & 37.32 & 4.18 & 18.35 \\
\hline ZIF-90 + AF 647 & 38.01 & 4.46 & 18.60 \\
\hline ZIF-90 (TBA) & 33.54 & 3.71 & 19.32 \\
\hline ZIF-90 (TEA) & 32.44 & 3.84 & 18.70 \\
\hline
\end{tabular}



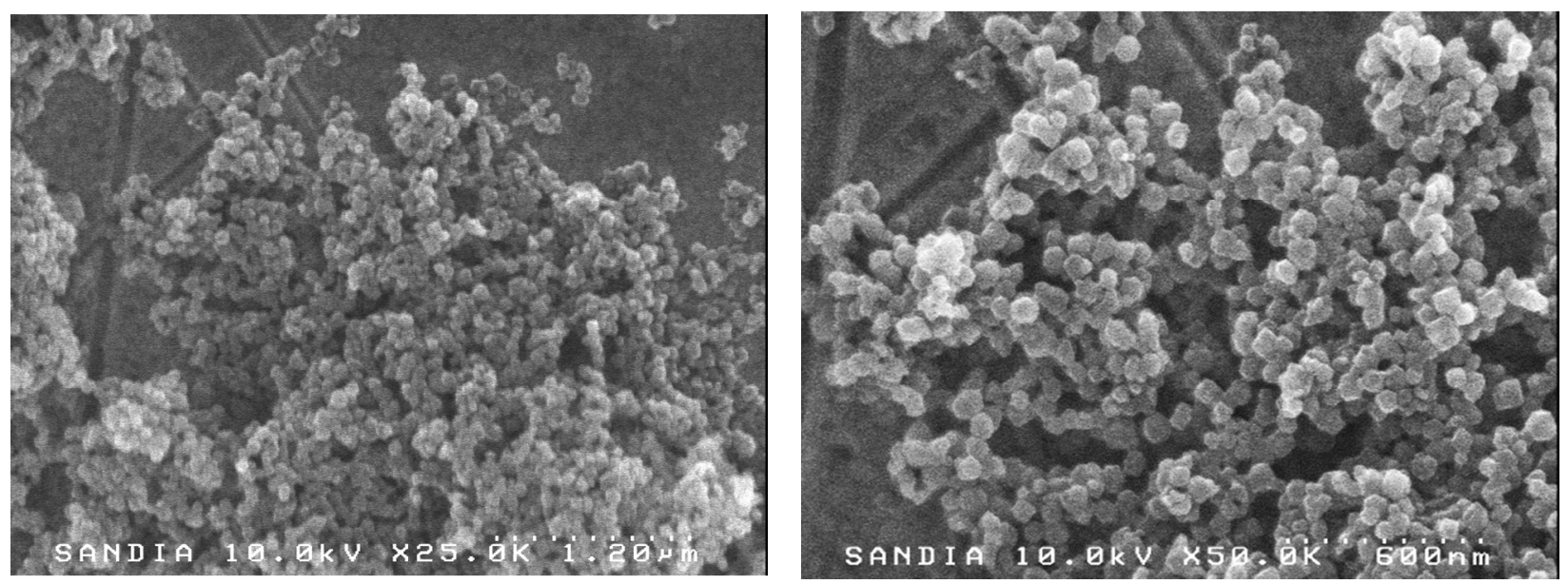

Figure S2. SEM images of ZIF-90 particles using the standard room temperature synthesis procedure $\left(\mathrm{Zn}\left(\mathrm{NO}_{3}\right)_{2}\right.$, HIca, DMF and TOA).

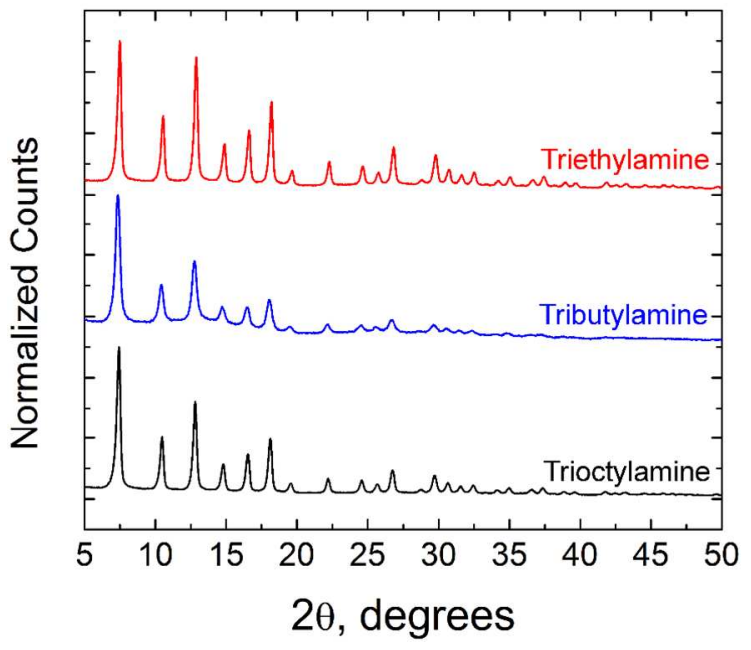

Figure S3. XRD patterns for ZIF-90 synthesized with triethylamine, tributylamine, and trioctylamine. 

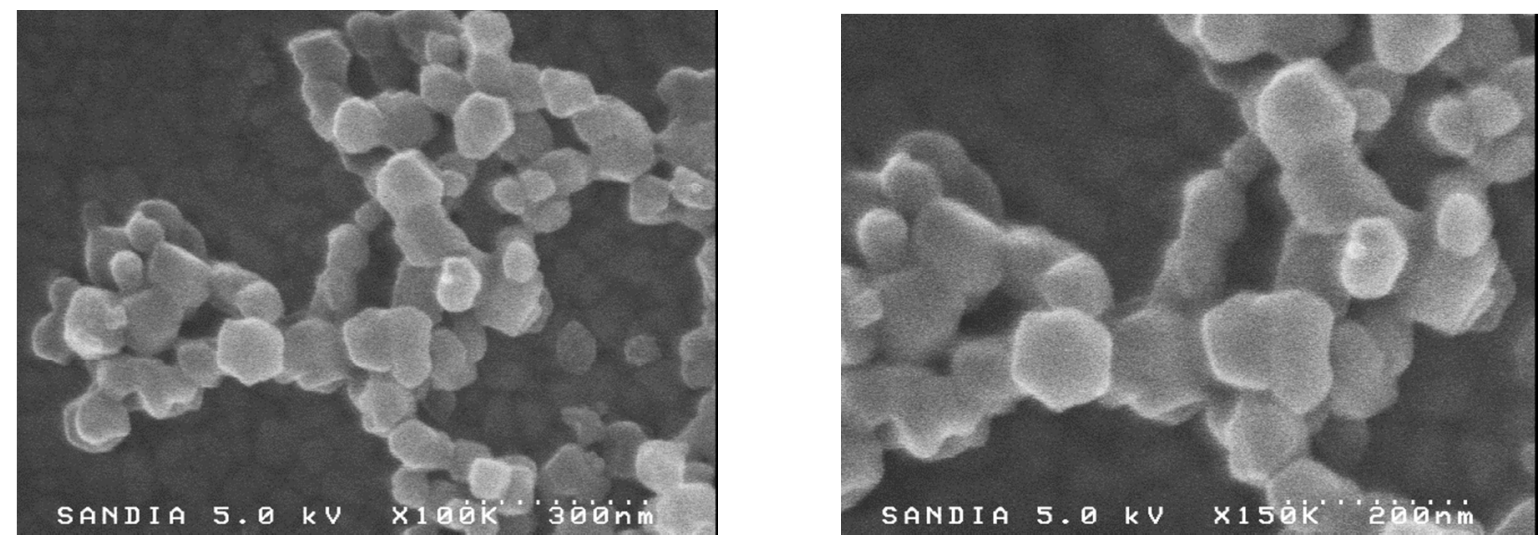

Figure S4. SEM images of ZIF-90 particles synthesized with tributylamine.
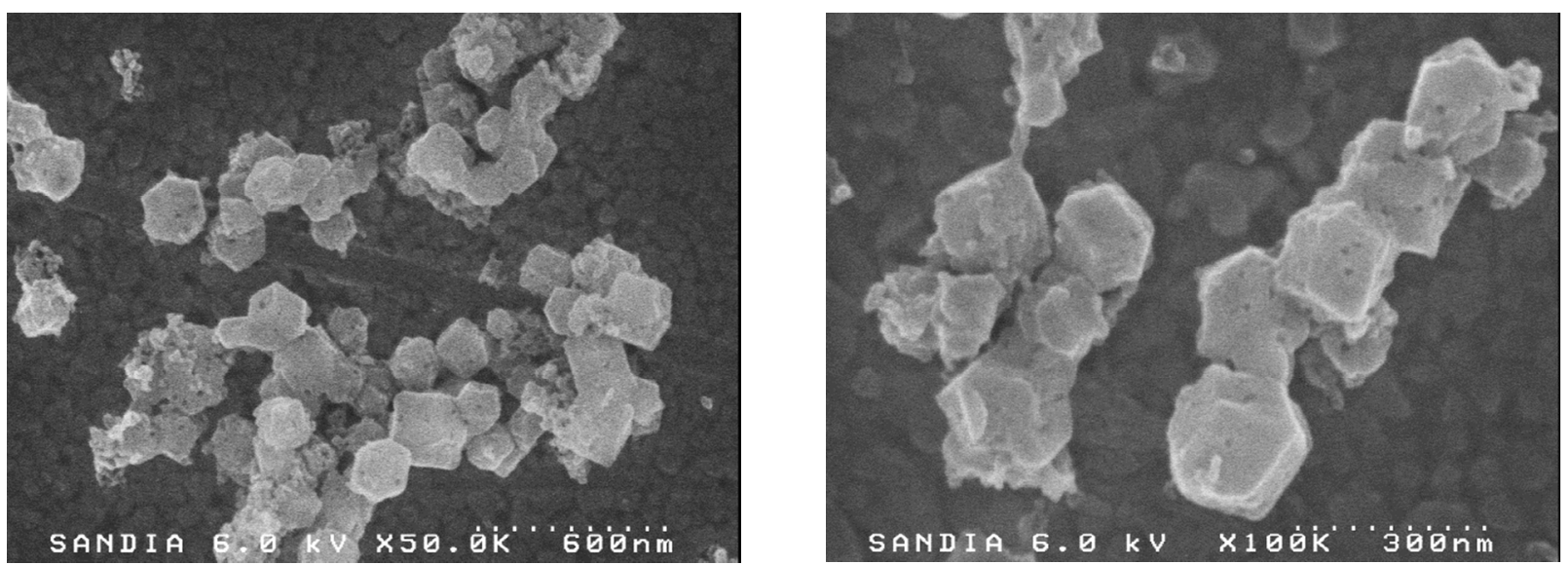

Figure S5. SEM images of ZIF-90 particles synthesized with triethylamine.
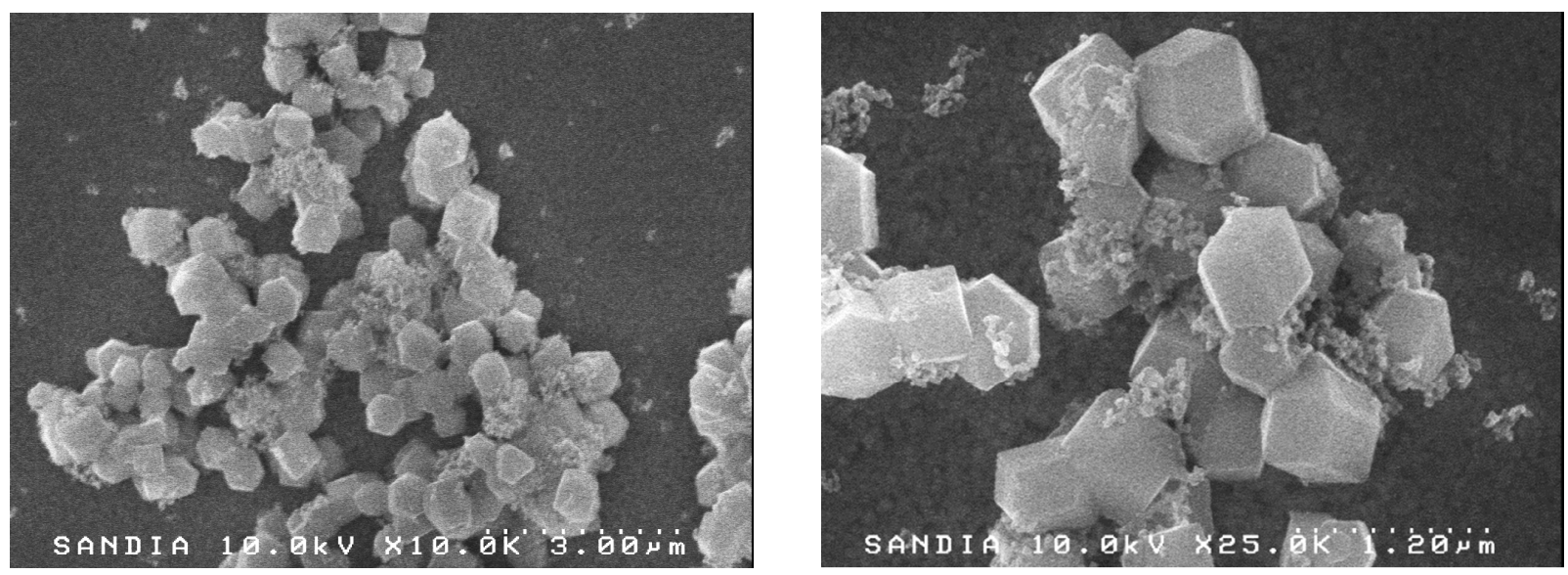

Figure S6. SEM images of ZIF-90 particles synthesized in trioctylamine at $150{ }^{\circ} \mathrm{C}$. 

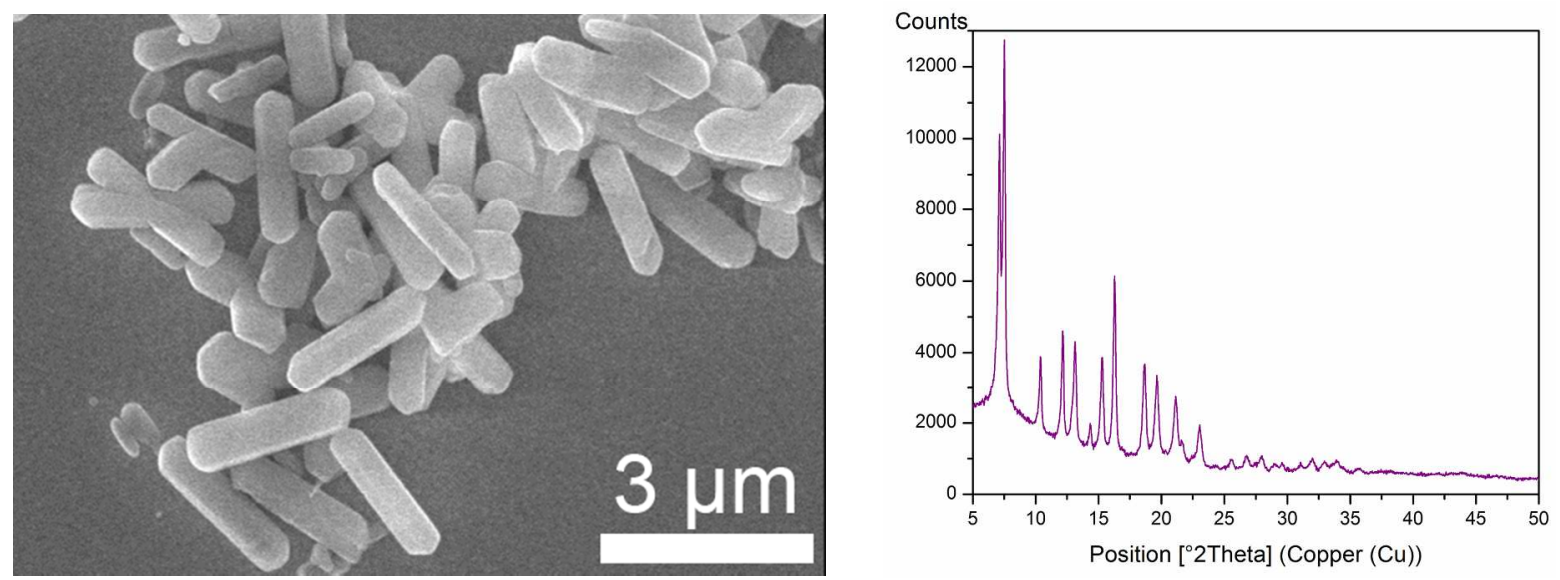

Figure S7. SEM image of ZIF-7 microrods formed at $150{ }^{\circ} \mathrm{C}$ after 60 minutes (left) and the corresponding PXRD pattern (right).
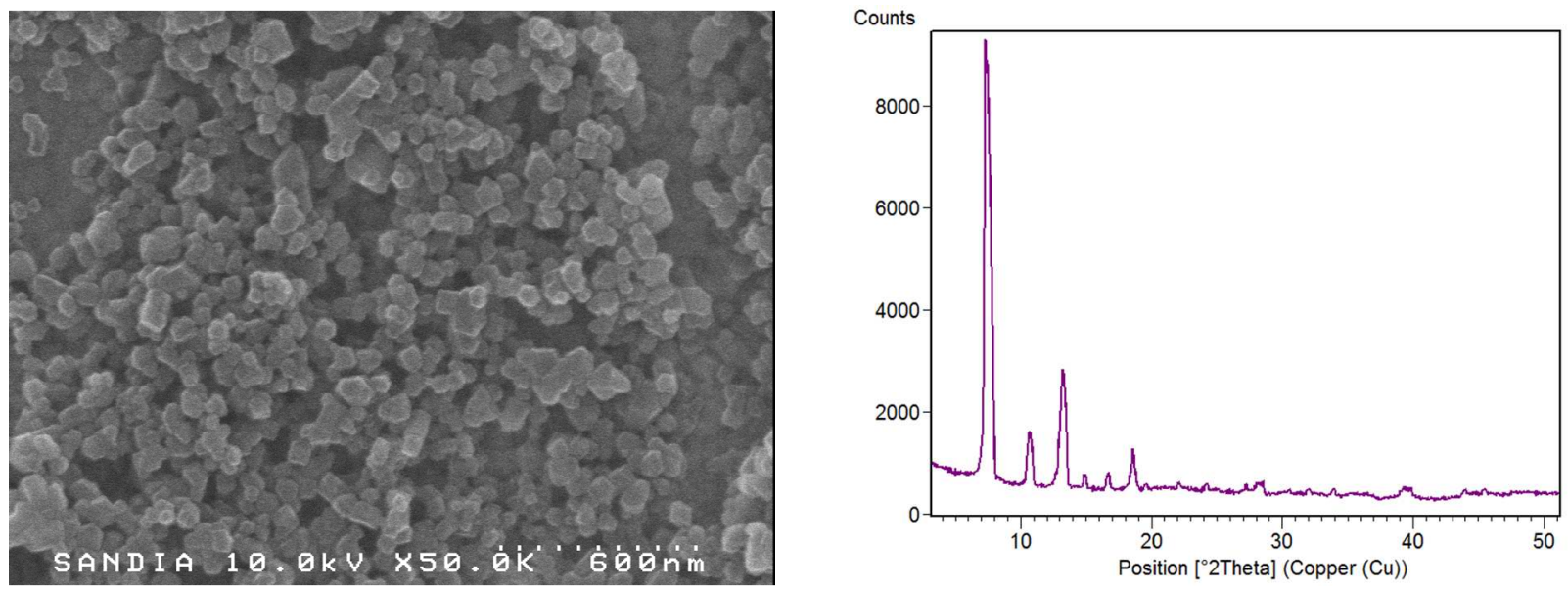

Figure S8. SEM image of ZIF-8 nanoparticles formed at $150{ }^{\circ} \mathrm{C}$ after $60 \mathrm{~min}$ (left) and the corresponding PXRD pattern (right). 

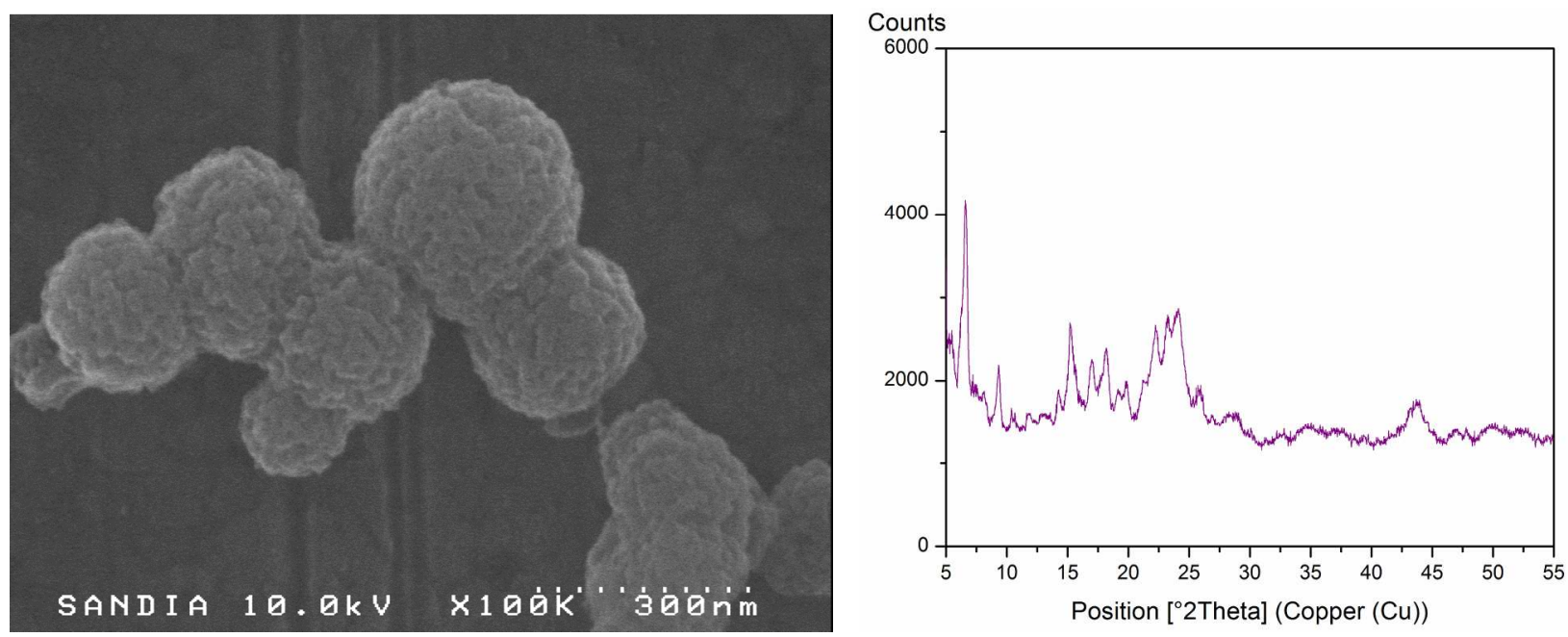

Figure S9. SEM image of TIF-2 particles formed solvothermally at $150{ }^{\circ} \mathrm{C}$ after 48 hours (left) and the corresponding PXRD pattern (right).
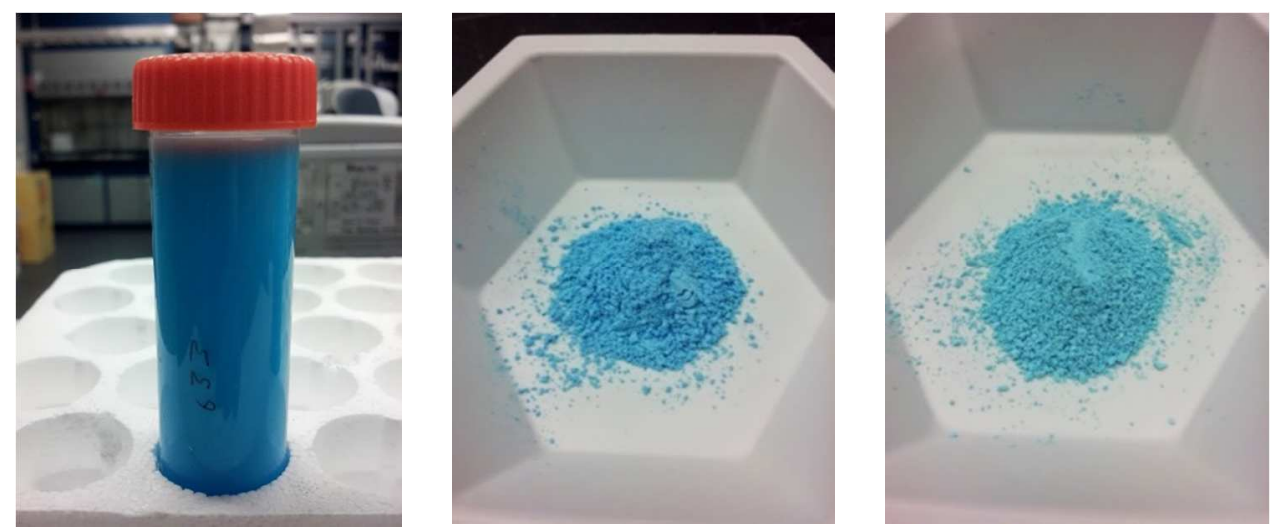

Figure S10. Suspended ZIF-90 particles in dye solution (left) and isolated particles labeled with Alexa Fluor 633 (middle) and Alexa Fluor 647 (right). 


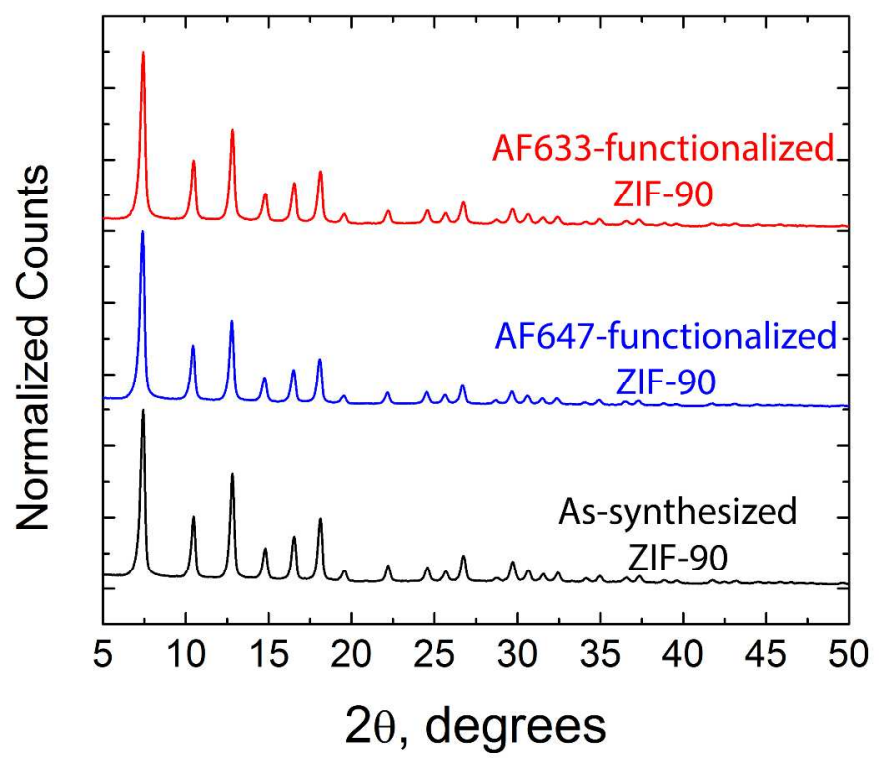

Figure S11. XRD patterns for the rt-synthesized ZIF-90 NPs before and after fluorescent labeling with either Alexa Fluor ${ }^{\circledR} 633$ Hydrazide or Alexa Fluor ${ }^{\circledR} 647$ Hydrazide.
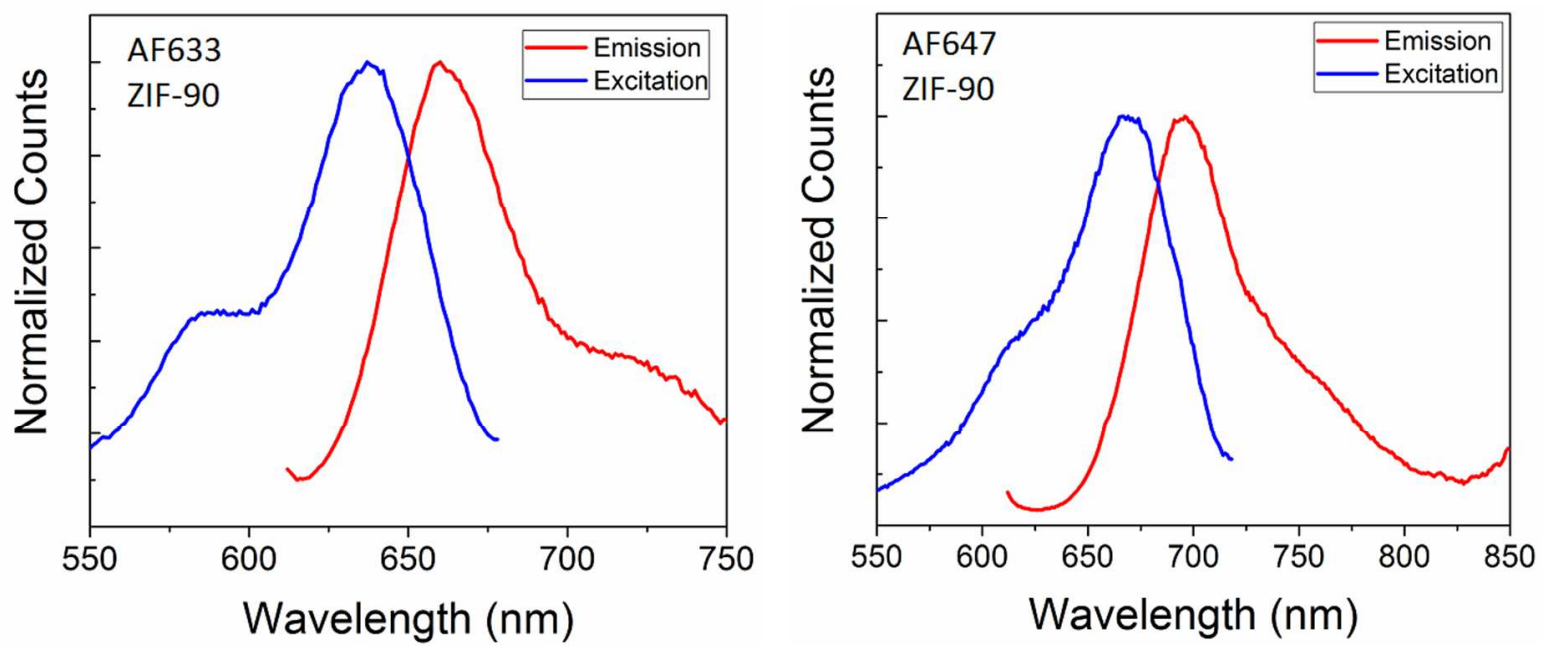

Figure S12. Fluorescence spectra of Alexa Fluor ${ }^{\circledR} 633$ functionalized ZIF-90 (left) and Alexa Fluor ${ }^{\circledR}$ 647 functionalized ZIF-90 (right). 


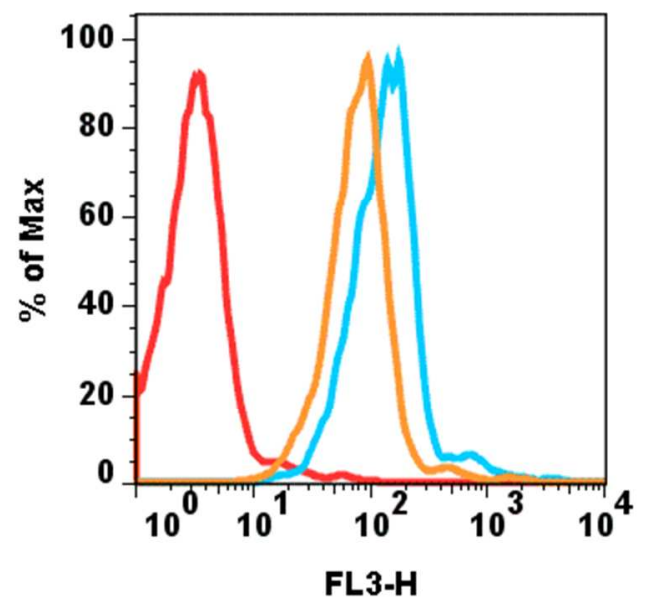

Figure S13. Representative flow cytometry histograms of $1 \times 10^{6} \mathrm{CHO}-\mathrm{K} 1$ cells that were untreated (red histogram) or incubated with $10 \mu \mathrm{g} / \mathrm{mL}$ of Alexa Fluor 647-labeled ZIF-90 NPs for 1 hour at $37^{\circ} \mathrm{C}$ (cyan histogram) before being analyzed for far red fluorescence (FL3) using a FACSCalibur flow cytometer; cells were then treated with trypsin to remove surface-bound ZIF-90 and analyzed again (orange histogram). 